\title{
Field efficacy of eprinomectin against a natural Muellerius capillaris infection in dairy goats
}

\author{
Thomas Geurden*, Jozef Vercruysse \\ Laboratory of Parasitology, Faculty of Veterinary Medicine, Ghent University, Salisburylaan 133, B-9820 Merelbeke, Belgium
}

Received 5 March 2007; received in revised form 2 April 2007; accepted 4 April 2007

\begin{abstract}
The field efficacy of eprinomectin against a natural infection with Muellerius capillaris was evaluated in adult dairy goats. A total of 13 animals were included in a crossover treatment study. Animals were treated with eprinomectin $(0.5 \mathrm{mg} / \mathrm{kg}) \mathrm{in}$ the spring and again in the autumn of 2006, and monitored by enumeration of the lungworm larvae per gram of faeces (LPG). The reduction in LPG on days 7, 21 and 42 after treatment was used to evaluate the anthelmintic efficacy. Both in the spring and in the autumn a $100 \%$ reduction $(P<0.01)$ in LPG was observed on days 21 and 42 . These results illustrate that eprinomectin applied as a topical pour-on is a practical alternative to benzimidazole treatment of lungworms in dairy goats. No adverse reactions to the eprinomectin treatment were observed.
\end{abstract}

(C) 2007 Elsevier B.V. All rights reserved.

Keywords: Goats-nematoda; Muellerius capillaris; Eprinomectin; Field efficacy

\section{Introduction}

The small lungworm Muellerius capillaris is a common parasite of grazing goats worldwide. Although the clinical outcome of a M. capillaris infection seems more pronounced in goats compared to sheep (Beresford-Jones, 1967), most often goats do not display clear clinical symptoms except in heavy infections. The clinical symptoms include failure to thrive, coughing, dyspnea and sometimes mortality. In adult dairy goats infection can also result in depressed milk production (Bliss and Greiner, 1985). For the treatment of lungworm infections in goats, several benzimidazole compounds, such as fenbendazole, albendazole, cambendazole and oxfendazole (Cremers, 1983; Bliss and Greiner, 1985; Helle, 1986), and the probenzimidazole

\footnotetext{
* Corresponding author. Tel.: +329264 73 93; fax: +329264 7496 E-mail address: thomas.geurden@ugent.be (T. Geurden).
}

netobimine (Cabaret, 1991) were shown to reduce the larval excretion, although not completely.

Eprinomectin is an unapproved topically applied potent macrocyclic lactone (ML), subject to minimal partioning into milk of lactating goats (Dupuy et al., 2001). Although it is therefore a promising alternative for benzimidazole treatment, the efficacy of eprinomectin against lungworms in dairy goats has not yet been evaluated. Furthermore, the need for a higher dose rate for anthelmintic treatment was previously suggested based on the low plasma concentration of eprinomectin in goats after topical application (Alvinerie et al., 1999). For the treatment of gastrointestinal nematodes, such as Teladorsagia circumcinta and Trichostrongylus colubriformis, eprinomectin was indeed shown to be effective in reducing faecal egg counts (Cringoli et al., 2004) and worm burdens (Chartier and Pors, 2004) in goats, when twice the cattle dose rate $(1 \mathrm{mg} / \mathrm{kg}$ bodyweight $)$ was applied. It is however not certain if a similar double dose rate is required for treatment of a natural $M$. capillaris 
infection. Therefore, in the present study the field efficacy of a topical pour-on application at a dose rate of $0.5 \mathrm{mg} / \mathrm{kg}$ against a natural $M$. capillaris infection was evaluated.

\section{Materials and methods}

A crossover study design was used to evaluate the field efficacy of eprinomectin in adult dairy goats (Toggenburger), following the guidelines described by Vercruysse et al. (2001). Animals were allowed to graze throughout the year, and had access to shelter at all time. In the spring of 2006, 10 animals were selected based on faecal excretion of larvae: 4 animals were randomly assigned to the control group and 6 animals to the treatment group. None of these goats had been treated with an anthelmintic for at least 1 year prior to the study. The lenght of the washout period was based on the knowledge that the systemic availability of eprinomectin in goats is less than in cattle (Alvinerie et al., 1999) and that the remanent efficacy is maximum 28 days in cattle (Cramer et al., 2000). After a washout period of 6 months, 13 animals were selected for the second treatment in the autumn of 2006. These included 9 of the 10 animals used in the spring. One animal (Animal No. 2) was not selected in the autumn, due to absence of larvae prior to treatment. Four first grazing season goats were added to the study. The six animals which had been treated in the spring were assigned to the control group. The three animals of the spring control group and the four additional animals were assigned to the treatment group. All animals in the treatment groups were weighed using a calibrated scale and received a pour-on application of eprinomectin at a dose rate of $0.5 \mathrm{mg} / \mathrm{kg}$.

Prior to treatment (D0), and 7 (D7), 21 (D21) and 42 (D42) days after treatment individual faecal samples were taken from all animals included in the study. The number of larvae per gram of faeces (LPG) was determined using the Baermann technique which has been shown to be a reliable diagnostic assay for the detection of lungworm larvae in goats (Papadopoulos et al., 2004). Identification of larvae was performed based on morphological characteristics (Hiepe et al., 1985). The geometric mean LPG was calculated at each sampling day. The treatment efficacy was measured based on the reduction in LPG for the animals in the treatment group compared to the control group. The reduction in larval excretion was calculated using the Henderson-Tilton formula (Henderson and Tilton, 1955):

$100 \times\left\lfloor 1-\frac{\mathrm{Ta} \times \mathrm{Cb}}{\mathrm{Tb} \times \mathrm{Ca}}\right\rfloor$
$\mathrm{Tb}$ and $\mathrm{Ta}$ being the geometric mean LPG in the treatment group before and after treatment, and $\mathrm{Cb}$ and $\mathrm{Ca}$ being the geometric mean LPG in the control animals before and after treatment. Differences in larval excretion were analysed using a Mann-Whitney test for pairwise comparison of the treatment group with the control group. Probability $(P)$ values $<0.05$ were considered to indicate significant differences.

\section{Results}

At all sampling days the larvae retrieved from the Baermann were identified as $M$. capillaris. The individual LPG, the geometric mean LPG and the percentage reduction of the spring treatment are presented in Table 1. Both in the treatment group and the control group all animals were positive prior to treatment. The LPG was significantly $(P<0.01)$ lower in the treatment group compared to control group at D21 and D42. The results for the treatment in autumn are presented in Table 2. Both in the treatment group and the control group all animals were positive prior to treatment. The LPG was significantly $(P<0.01)$ lower in the treatment group compared to control group at D7, D21 and D42. None of the control animals displayed clinical symptoms of lungworm infection during the follow-up period. Both in the spring and in the autumn none of the treated animals displayed adverse reactions during or after treatment.

Table 1

The individual LPG and the geometric mean (gmean) LPG in the control $(\mathrm{C})$ and treatment $(\mathrm{T})$ group on the different sampling days (D), and the percentage reduction (red) for the spring treatment

\begin{tabular}{llrrrr}
\hline Animal no. & Group & LPG D0 & LPG D7 & LPG D21 & LPG D42 \\
\hline 1 & $\mathrm{C}$ & 1 & 5 & 2 & 1 \\
2 & $\mathrm{C}$ & 15 & 3 & 4 & 2 \\
3 & $\mathrm{C}$ & 10 & 4 & 1 & 4 \\
4 & $\mathrm{C}$ & 19 & 3 & 4 & 3 \\
gmean & & 8 & 2 & 2 & 2 \\
5 & & & & & \\
6 & $\mathrm{~T}$ & 1 & 6 & 0 & 0 \\
7 & $\mathrm{~T}$ & 7 & 7 & 0 & 0 \\
8 & $\mathrm{~T}$ & 14 & 30 & 0 & 0 \\
9 & $\mathrm{~T}$ & 16 & 8 & 0 & 0 \\
10 & $\mathrm{~T}$ & 17 & 5 & 0 & 0 \\
gmean & $\mathrm{T}$ & 45 & 24 & 0 & 0 \\
red & & 11 & 2 & 0 & 0 \\
\hline
\end{tabular}

Significant $(P<0.01)$. 
Table 2

The individual LPG and the geometric mean (gmean) LPG in the control (C) and treatment ( $\mathrm{T}$ ) group on the different sampling days (D), and the percentage reduction (red) for the autumn treatment

\begin{tabular}{llcccc}
\hline Animal no. & Group & LPG D0 & LPG D7 & LPG D21 & LPG D42 \\
\hline 5 & $\mathrm{C}$ & 2 & 2 & 3 & 15 \\
6 & $\mathrm{C}$ & 4 & 3 & 4 & 18 \\
7 & $\mathrm{C}$ & 6 & 7 & 10 & 4 \\
8 & $\mathrm{C}$ & 8 & 9 & 1 & 2 \\
9 & $\mathrm{C}$ & 91 & 56 & 7 & 3 \\
10 & $\mathrm{C}$ & 4 & 6 & 3 & 7 \\
gmean & & 8 & 7 & 4 & 6 \\
1 & & & & & \\
3 & $\mathrm{~T}$ & 10 & 1 & 0 & 0 \\
4 & $\mathrm{~T}$ & 160 & 0 & 0 & 0 \\
11 & $\mathrm{~T}$ & 13 & 3 & 0 & 0 \\
12 & $\mathrm{~T}$ & 7 & 0 & 0 & 0 \\
13 & $\mathrm{~T}$ & 5 & 1 & 0 & 0 \\
14 & $\mathrm{~T}$ & 2 & 0 & 0 & 0 \\
gmean & $\mathrm{T}$ & 1 & 0 & 0 & 0 \\
red & & 9 & 0 & 0 & 0 \\
\hline
\end{tabular}

* Significant $(P<0.01)$.

\section{Discussion}

This is the first study to evaluate the field efficacy of eprinomectin against a natural $M$. capillaris infection in adult dairy goats. The results of the present study indicate the high efficacy of eprinomectin at a dose rate of $0.5 \mathrm{mg} / \mathrm{kg}$ bodyweight against a natural $M$. capillaris infection. For the treatment of gastrointestinal nematodes in goats, a double dose ( $1 \mathrm{mg} / \mathrm{kg}$ bodyweight) has been recommended (Chartier and Pors, 2004; Cringoli et al., 2004; de Souza Chagas et al., 2007), based on the low concentration of eprinomectin in plasma after topical application (Alvinerie et al., 1999). The results of the present study however suggest that $M$. capillaris is not a dose limiting species and indicate that treatment with eprinomectin at a lower dose rate of $0.5 \mathrm{mg} / \mathrm{kg}$ bodyweight significantly reduced the larval excretion in goats. Reduction of larval excretion does not implicate that animals are no longer infected, due to the specific location of the adult worms in the lung parenchym (Papadopoulos et al., 2004; Rehbein and Visser, 2002), but does lower the infection of the intermediate host snail population and will subsequently reduce the exposure of animals to infection on pasture, preventing continuous re-infection and the development of clinical symptoms and production losses.

In sheep, both ivermectin (oral administration) and moxidectin (oral and subcutaneous administration) have been shown to effectively reduce the lungworm burden and faecal excretion of lungworm larvae (Papadopoulos et al., 2004; Rehbein and Visser, 2002). However, both have a milk-withdrawal period in sheep and cattle. Since the maximum level of residue in goat milk was shown to remain below the maximum acceptable level permitted in lactating cattle (Dupuy et al., 2001; Anastasio et al., 2005), the major advantage of eprinomectin over moxidectin and ivermectin, is the subsequent zero milk-withdrawal period (Dupuy et al., 2001; Anastasio et al., 2005). Eprinomectin is however not registered for use in goats.

\section{References}

Alvinerie, M., Lacoste, E., Sutra, J.F., Chartier, C., 1999. Some pharmacokinetic parameters of eprinomectin in goats following pour-on administration. Vet. Res. Commun. 23, 449-455.

Anastasio, A., Veneziano, V., Capurro, E., Rinaldi, L., Cortesi, M.L., Rubino, R., Danaher, M., Cringoli, G., 2005. Fate of eprinomectin in goat milk and cheeses with different ripening times following pour-on administration. J. Food. Prot. 68, 1097-1101.

Beresford-Jones, W.P., 1967. Observations on Mellerius capillaris (Muller 1889). Res. Vet. Sci. 8, 272-279.

Bliss, E.L., Greiner, E.C., 1985. Efficacy of fenbendazole and cambendazole against Muellerius capillaris in dairy goats. Am. J. Vet. Res. 46, 1923-1925.

Cabaret, J., 1991. Efficacy of netobimin against Muellerius capillaris and resistant strain of digestive tract strongyles in dairy goats. Am. J. Vet. Res. 52, 1313-1315.

Chartier, C., Pors, I., 2004. Duration of activity of topical eprinomectin against experimental infections with Teladorsagia circumcincta and Trichostrongylus colubriformis in goats. Vet. Parasitol. 125, 415-419.

Cramer, L.G., Pitt, S.R., Rehbein, S., Gogolewski, R.P., Kunkle, B.N., Langhoff, W.K., Bond, K.G., Maciel, A.E., 2000. Persistent efficacy of topical eprinomectin against nematode parasites in cattle. Parasitol. Res. 86, 944-946.

Cremers, H.J., 1983. Effectiveness of oxfendazole against Muellerius capillaris (Nematoda: Protostrongylidae) in goats. Tijdschr. Diergeneeskd. 108, 863-867.

Cringoli, G., Rinaldi, L., Veneziano, V., Capelli, G., Rubino, R., 2004 Effectiveness of eprinomectin pour-on against gastrointestinal nematodes of naturally infected goats. Small Rumin. Res. 55, 209-213.

de Souza Chagas, A.C., da Silva Vieira, L., Rodrigues Aragao, W., do Carmo Navarro, A.M., Vasques Villela, L.C., 2007. Anthelmintic action of eprinomectin in lactating Anglo-Nubian goats in Brazil. Parasitol. Res. 100, 391-394.

Dupuy, J., Chartier, C., Sutra, J.F., Alvinerie, M., 2001. Eprinomectin in dairy goats: dose influence on plasma levels and excretion in milk. Parasitol. Res. 87, 294-298.

Helle, O., 1986. The efficacy of fenbendazole and albendazole against the lungworm Muellerius capillaris in goats. Vet. Parasitol. 22, 293-301.

Henderson, C.F., Tilton, E.W., 1955. Tests with acaricides against the brown wheat mite. J. Econ. Entomol. 48, 157-161.

Hiepe, T., Buchwalder, R., Nickel, S., 1985. Teaching Book for Parasitology, vol.3, Veterinary Helminthology (De) Gustav Fisher Verlag, Jena, Germany. 
Papadopoulos, E., Sotiraki, S., Himonas, C., Fthenakis, G.C., 2004. Treatment of small lungworm infestation in sheep by using moxidectin. Vet. Parasitol. 121, 329-336.

Rehbein, S., Visser, M., 2002. Efficacy of ivermectin delivered via a controlled-release capsule against small lungworms (Protostron- gylidae) in sheep. J. Vet. Med. B: Infect. Dis. Vet. Public Health 49, 313-316.

Vercruysse, J., Holdsworth, P., Letonja, T., Barth, D., Conder, G., Hamamoto, K., Okano, K., 2001. International harmonisation of anthelmintic efficacy guidelines. Vet. Parasitol. 96, 171-193. 